\title{
Extracorporeal Lung Assist for Two Cases of Severe Acute Respiratory Failure
}

\author{
Kyoji Tsuno, Hidenori Terasaki, Taisuke Okamoto, \\ Ryuji Tsursumi, Tohru Morioka, and Tadahiro KatsuYa*
}

(Key words: Acute respiratory failure, barotrauma, artificial membrane lung)

Mechanical pulmonary ventilation (MV) is routinely used for patients with acute respiratory failure (ARF). High airway pressures are at times required to attain alveolar ventilation according to the lung stiffness. However, Kolobow et al. ${ }^{1-3}$ have recently warned of the insulting effects of MV on the healthy lung. They suggest that the upper safety limit of lung inflation should be less than 3 times of the normal tidal volume and/or less than $30 \mathrm{cmH}_{2} \mathrm{O}$ of the peak inspiratory pressure (PIP). MV with a high PIP might iatrogenically cause overinflation of the still functioning healthy alveoli in the damaged lungs, and worsen ARF.

A PIP of over $50 \quad \mathrm{cmH}_{2} \mathrm{O}$ was necessary for two critically ill patients with ARF during conventional $\mathrm{MV}$, and a lifethreatening barotrauma developed. They were treated with veno-venous extracorporeal bypass with an artificial membrane lung (ML). The PIP was lowered to 30 $35 \mathrm{cmH}_{2} \mathrm{O}$ or less by decreasing the tidal volume $\left(\mathrm{V}_{\mathrm{T}}\right)$ during the bypass, and it resulted in an improvement in the lungs.

\section{Case Reports}

Patient One

An 18-yr-old female, $50 \mathrm{~kg}, 158 \mathrm{~cm}$,

Department of Anesthesiology, *Intensive Care Unit, Kumamoto University Medical School, Kumamoto, Japan

Address reprint requests to Dr. 'Tsuno: Department of Anesthesiology, Kumamoto University Medical School, 1-1-1 Honjyo, Kumamoto 860, Japan without a particular past history, had a traffic accident. Consciousness was normal and there seemed no serious injuries at first. However, two hours after the accident, she became dyspneic. Pulmonary infiltration was found on a chest roentgenogram, wet rales were audible, and bloody foamy tracheal secretion gradually increased. The patient was diagnosed as having posttraumatic pulmonary edema. MV was started 12 hours after the traffic accident. Respiratory failure rapidly progressed in spite of all therapeutic efforts, and hypotension around $70 \mathrm{mmHg}$ continued. Subcutaneous and mediastinal emphysema developed. Cardiac arrest occurred due to a hypoxemia of less than $50 \mathrm{mmHg}$ of $\mathrm{Pa}_{\mathrm{O}_{2}}$ and a hypopotassemia of $2.88 \mathrm{mEq} / \mathrm{L}$. Though the patient was successfully resuscitated, a $\mathrm{Pa}_{\mathrm{O}_{2}}$ of $45-55 \mathrm{mmHg}$ continued even under $\mathrm{MV}$ with $\mathrm{FI}_{\mathrm{O}_{2}}$ 1.0, PEEP $20 \mathrm{cmH}_{2} \mathrm{O}$, and a PIP over $60 \mathrm{cmH}_{2} \mathrm{O}$. A veno-venous extracorporeal lung assist (ECLA) with an artificial ML was planned ${ }^{4}$.

A 32 Fr. catheter was inserted from the right internal jugular vein into the right atrium and a smaller one to a distal portion of the same vein for blood drainage, and a $24 \mathrm{Fr}$. catheter was inserted into the right femoral vein for blood return. The extracorporeal circuit included a roller pump, a reservoir with a maximal capacity of $80 \mathrm{ml}$, an autoregulator which detects the reservoir volume and transmits on-off signals to the pump switch, and a Kolobow membrane lung (SciMed, USA) with a 
surface area of $2.5 \mathrm{~m}^{2}$. The circuit was filled with $\mathrm{CO}_{2}$ to remove air inside, then primed with $1.5 \mathrm{~L}$ of heparinized Hartman's solution with a $\mathrm{pH} 8$ by negative pressure applied on the gas phase of the ML. The Hartman's solution was partially replaced later by $1.1 \mathrm{~L}$ of heparinized fresh blood.

After the start of ECLA with a bypass flow of $2.0-2.7 \mathrm{~L} / \mathrm{min}$, the setting of the MV was changed to decrease the tidal volume from $700 \mathrm{ml}$ to $300-400 \mathrm{ml}$, and the PEEP from $20 \mathrm{cmH}_{2} \mathrm{O}$ to $10 \mathrm{cmH}_{2} \mathrm{O}$. PIP was maintained at $30-35 \mathrm{cmH}_{2} \mathrm{O}$. The patient responded rapidly to ECLA. Under ECLA and intermittent mandatory ventilation (IMV), the $\mathrm{Fo}_{2}$ to both the patient and the ML could be reduced to 0.6 within 5 hours to maintain the $\mathrm{PaO}_{2}$ at 70 $80 \mathrm{mmHg}$. Hypotension was easily corrected by the administration of dopamine of a quarter to a half of the doses given before the start of ECLA $(20-30 \gamma / \mathrm{kg} / \mathrm{min})$. The foamy bloody tracheal secretion, containing $5.4 \mathrm{~g} / \mathrm{dl}$ of protein before ECLA, decreased and changed to a serum-like yellow fluid with $1.4 \mathrm{~g} / \mathrm{dl}$ of protein within 26 hours of ECLA. She was weaned from ECLA after 46.5 hours, and put on IMV with an $\mathrm{Fi}_{\mathrm{O}_{2}}$ of 0.4 and a PEEP of $10 \mathrm{cmH}_{2} \mathrm{O}$. Arterial blood gases showed a $\mathrm{Po}_{2}$ of $119 \mathrm{mmHg}$, a $\mathrm{PCO}_{2}$ of $39.9 \mathrm{mmHg}$, and a $\mathrm{pH}$ of 7.451 just after the weaning. The endotracheal tube was removed 2 days after the weaning from ECLA. The patient was discharged from the hospital on the 14th day after the weaning from ECLA.

\section{Patient Two}

An 11-yr-old female, $31 \mathrm{~kg}, 140 \mathrm{~cm}$ was admitted into the ICU for ARF and renal failure. She was known to have proteinuria and hematuria since the age of 6 , and diagnosed as having moderate proliferative glomerulonephritis when she was $10-y r-$ old. She had been given cyclophosphamide, prednisolone, dipyridamole, and warfarin potassium. Recently, proteinuria and hematuria became manifest, and heparin (300 $\mathrm{U} / \mathrm{kg} /$ day) and dilazep administrations were started. However, they were ineffective. On admission, she had the following prob- lems; tachypnea (60 breaths/min), pulmonary bleeding, systemic cyanosis, hypoxemia ( $\mathrm{pHa} 7.335, \mathrm{PaO}_{2} 40.2 \mathrm{mmHg}, \mathrm{PaCO}_{2}$ $31.2 \mathrm{mmHg}, B E-8.5 \mathrm{mEq} / \mathrm{L}$, under an insufflation of $3 \mathrm{~L} / \mathrm{min}$ of $\mathrm{O}_{2}$ ), anemia ( $\mathrm{RBC}$ $1.63 \times 10^{6} / \mathrm{mm}^{3}, \mathrm{Hb} 4.6 \mathrm{~g} / \mathrm{dl}$, Ht $\left.13.8 \%\right)$, renal insufficiency (s-BUN $75 \mathrm{mg} / \mathrm{dl}, \mathrm{s}-\mathrm{Cr}$ $4.3 \mathrm{mg} / \mathrm{dl}$, Ccre $22 \mathrm{ml} / \mathrm{min}$ ), and hemorrhagic diathesis (PT $21.5 \mathrm{sec} 18 \%$, APTT $94.1 \mathrm{sec} 32 \%$ ). She was put on a regimen of MV, $\gamma$-globulin, massive doses of steroids, antibiotics, and others. However, pulmonary failure became worse and worse over 2 days. Subcutaneous and mediastinal emphysema developed. Pulmonary bleeding continued, and bloody foamy pulmonary secretions increased. Bronchofiberscopy was tried several times without success to find any particular bleeding sites. Under conventional MV with $100 \%$ oxygen, respiratory rate (RR) of 50 times/min, PIP over 50 $\mathrm{cmH}_{2} \mathrm{O}$, PEEP of $10 \mathrm{cmH}_{2} \mathrm{O}$, the arterial blood gases showed $\mathrm{pH} 7.279, \mathrm{Po}_{2} 47.9$ $\mathrm{mmHg}, \mathrm{PCO}_{2} 49.6 \mathrm{mmHg}$, and $\mathrm{BE}-3.9$ $\mathrm{mEq} / \mathrm{L}$ on the 6 th day in the ICU. Anemia, hemorrhagic diathesis, and renal failure continued. Severe infiltration in the entire lung field and mediastinal emphysema were further advanced, and endangered the life. An application of ECLA was considered as a means of life support at this time.

A spiral-embedded thin wall catheter of polyurethane, $0.3 \mathrm{~mm}$ in thickness and 7.4 $\mathrm{mm}$ in internal diameter (Kuraray, Japan), was inserted into the right atrium for blood drainage through the right internal jugular vein. The distal portion of the same vein was also cannulated with a smaller one for venous drainage. The right saphenous vein was cannulated for blood return. One SciMed Kolobow lung, with a surface area of $4.5 \mathrm{~m}^{2}$, was used. The priming of the extracorporeal circuit was done as in case 1. The extracorporeal bypass flow was 2.8 $\mathrm{L} / \mathrm{min}$. During ECLA, the patient was mechanically ventilated with a small tidal volume, about $100 \mathrm{ml}$, with a PIP around $30 \mathrm{cmH}_{2} \mathrm{O}$ and a PEEP of $15 \mathrm{cmH}_{2} \mathrm{O}$, and with an RR of 15-20 times/min.

Within 9 hours of ECLA, $\mathrm{Fo}_{2}$ to both 
the patient and the $\mathrm{ML}$ could be reduced to 0.6 to maintain the $\mathrm{PaO}_{2}$ at $60-70$ mmHg. Lung function improved slowly, pulmonary bleeding ceased, and she became conscious. Subcutaneous and mediastinal emphysema, as well as pulmonary infiltration decreased on a chest roentgenogram. After 40 hours of ECLA, bleeding from the cannulation site at the neck became remarkable, though platelets remained at $1.08-1.29 \times 10^{5} / \mathrm{mm}^{3}$ and activated clotting time (ACT) had been maintained around $200 \mathrm{sec}$ with a careful control of heparin infusion all through the bypass. ECLA was gradually decreased by lowering the gas flow to the ML. She could tolerate conventional MV with $\mathrm{pHa}$ 7.370, $\mathrm{PaO}_{2} 66.1 \mathrm{mmHg}$, and $\mathrm{PaCO}_{2} 42.6 \mathrm{mmHg}$ under the ventilator setting $\mathrm{FI}_{\mathrm{O}_{2}}$ 0.7, PIP $35 \mathrm{cmH}_{2} \mathrm{O}$, PEEP $15 \mathrm{cmH}_{2} \mathrm{O}, \mathrm{RR} 30$ times/min, $V_{T} 300 \mathrm{ml}$, and without the support of extracorporeal gas exchange. She was disconnected after 47 hours of ECLA. On the 5th day after the disconnection, the endotracheal tube was removed under air spontaneous breathing. However, on the same day, pain and paresis appeared at the right upper extremity, and cerebral bleeding was found by CT scan. Craniotomy was done the next day, and the post operative courses were good. Unfortunately, a second cerebral bleeding occurred in an inoperable area on the 19 th day after the weaning from ECLA, and she died the next day.

\section{Discussion}

In the treatment of respiratory failure, the setting of a ventilator is tailored to maintain normocarbia. In a case of severe ARF, where lung compliance is low, high airway pressure is often required. Even in a damaged lung, however, there still exist healthy areas with good compliances, and they support the life. When a lung is ventilated as a whole with a high PIP, the healthy area will be overinflated and injured, and the previously damaged area might be deprived of natural healing. MV should not be adjusted to a decreased compliance of the already damaged area of the lung, but to a good compliance of the remaining healthy area. This adjustment of MV will develop a debt in gas exchange. However, the concomitant use of ECLA will compensate the debt of gas exchange and become life-saving.

In our 2 cases, especially in the second case, we adopted MV with a small tidal volume to ensure the small excursion of airway pressure and prevent overdistension of the healthy alveoli. Much the same, Gattinoni et al. ${ }^{5}$ adopted a low frequency positive pressure ventilation method under the support of $\mathrm{CO}_{2}$ removal by an extracorporeal V.V bypass to promote the natural healing of the lung pathology of ARF.

In case $1, a$ severe disturbance of pulmonary oxygenation, probably due to a V/Q imbalance during $M V$, was relieved rapidly during ECLA, and bloody foamy pulmonary secretions decreased remarkably, while the pathological healing might still have been incomplete. There might be a little chance to decrease the $\mathrm{V} / \mathrm{Q}$ imbalance by changing the setting of $\mathrm{MV}$ to a pressure-controlled-invertedratio-ventilation ${ }^{5}$. However, without the support of ECLA, we believe that this patient might have died or have taken a much longer time with much more suffering and cost under conventional MV.

Case 2 was suspected to have Goodpasture's syndrome, though an anti-basement membrane antibody was not found. Pulmonary healing was slow when compared with Case 1, but obvious. Bleeding from the cannulation sites became remarkable on the 3rd ECLA day and the bypass was discontinued though the pulmonary recovery was not yet sufficient. Bleeding tendency is the largest complication of prolonged extracorporeal circulation, and it often becomes the reason for the premature interruption of ECLA. We suppose that the intracranial bleeding in the second patient was attributable to the general vasculitis of her original disease. However, effects of prior administration of heparin, and decrement and dysfunction of platelets during bypass, on the intracranial bleeding, could not be 
ruled out.

Recently, a technique of heparin bonding to the surface of both the ML and extracorporeal circuit has been established ${ }^{6}$. One clinical case of ECLA without the systemic administration of heparin has already been reported from Sweden with great success at the workshop of extracorporeal elimination of $\mathrm{CO}_{2}$ with heparin-bonded equipment, on October 24-25, 1986. If the problem of bleeding during ECLA is solved, the indications of ECLA will be expanded to less critical patients and may contribute to reduce mortality from ARF.

(Received Jan. 6, 1988, accepted for publication Jun. 11, 1988)

\section{References}

1. Kolobow $T$, Moretti MP, Fumagalli $R$, Mascheroni D, Prato P, Chen V, Joris $M$ : Severe impairment in lung function induced by high peak airway pressure during mechanical ventilation. Am Rev Respir Dis 135:312-315, 1987

2. Tsuno K, Prato P, Kolobow T: Acute respiratory insufficiency induced by mechani- cal ventilation at peak airway pressure of $30 \mathrm{cmH}_{2} \mathrm{O}$. An experimental study. Am Rev Respir Dis 131:A154, 1985

3. Mascheroni D, Kolobow T, Fumagalli R, Moretti MP, Chen V, Buckhold D: Acute respiratory failure following induced hyperventilation. An experimental study. Am Rev Respir Dis 131:A333, 1985

4. Terasaki H, Nogami T, Saito Y, Otsu $\mathrm{T}$, Morioka $\mathrm{T}$ : Extracorporeal lung assist without endotracheal intubation and mechanical pulmonary ventilation. Crit Care Med 15:84, 1987

5. Gattinoni L, Pesenti A, Caspani ML, Pelizzola A, Mascheroni D, Marcolin $R$, Lapichino G, Langer M, Agostoni A, Kolobow T, Melrose DG, Damia D: The role of total static lung compliance in the management of severe ARDS unresponsive to conventional treatment. Intensive Care Med 10:121-126, 1984

6. Larm O, Larsson R, Olsson P: A new non-thrombogenic surface prepared by selective covalent binding of heparin via a modified reducing terminal residue. Biomat Med Dev Art Org 11:161-173, 1983 